\title{
Prestigiosa validação de nossos padrões editoriais
}

\author{
Harley E. A. Bicas, Cristina Muccioli, Mauro Goldchmit, Mauro S. O. Campos, Paulo E. Correa Dantas, Samir J. Bechara, \\ Vital Paulino Costa, Claudete N. Moral, Cláudia C. N. Moral, Edna Terezinha Rother, Maria Elisa Rangel Braga, \\ Paulo M. Imamura, Hanna Rotschild, Adamo Lui Netto, Henrique S. Kikuta, Elisabeto Ribeiro Gonçalves
}

Esta é uma das cartas mais sérias que cada um de nós pode haver já assinado e, no entanto, preparada em momento de enorme júbilo. Ela, ainda que devendo representar a humildade de cada contribuição isolada, não pode deixar de transmitir o profundo orgulho do conjunto por sua expressiva vitória. E, também, em meio à comemoração, não se omitir do chamamento de alerta para as responsabilidades advindas.

Sem dúvida, será possível citá-la como registro de uma circunstância histórica das mais importantes, pelo que simboliza não apenas em termos de valorizações acadêmicas de nossa produção científica mas, sobretudo, pelo que resgata da auto-estima de nossa gente. Não seria até exagero interpretar essa vitória como quase épica, pelas dificuldades superadas. Trata-se de anunciarmos, gloriosamente, por nossa participação no acontecido, impados de orgulho, o ingresso dos Arquivos Brasileiros de Oftalmologia na MEDLINE.

$\mathrm{E}$ - daí perguntarão muitos - o que significa isso e por que tanta agitação ? MEDLINE é a marca registrada da Medical Literature Analysis and Retrieval System Online, o mais importante sistema de compilação de informações sobre o que se produz mundialmente nas ciências da saúde, a base referencial de dados dessas publicações da National Library of Medicine, hoje disponibilizada pela rede mundial de computadores pelo endereço PubMed (www.pubmed.gov).

Atualmente, estima-se que a produção científica mundial em Medicina esteja entre quatro e cinco milhões de artigos por ano, o que significa ser absolutamente impossível um acompanhamento sobre o que se faz e escreve nessa área do conhecimento. A criação de um sistema de referências que selecione o que de melhor existe e que possua credibilidade para certificar a qualidade do veículo e, pois, indiretamente, a da publicação é, portanto, uma necessidade imperiosa da comunidade científica mundial, uma garantia para que essa própria produtividade tenha agilidade na sua auto-renovação e incentivo para se tornar ainda mais apurada. Obviamente, a característica principal desses sistemas de indexação é o elevado nível de exigibilidades, é o rigor com que impõem seus critérios de qualidade e de seleção, não apenas para ingresso, mas para conservação desse estado com que se distingue uma revista científica das demais. Daí, também, não surpreender que Universidades e agências de fomento à pesquisa científica (como nossos CNPq, CAPES, FINEP, FAPESP e outras) valorizem as publicações "indexadas", isto é, feitas em veículos que tenham tais certificados de qualidade.

Claro que esse estado de coisas apresenta uma face pro- fundamente perversa, a de que com ele se incentiva a publicação nos já consagrados (selecionados) periódicos, relegando aos emergentes uma condição inferiorizada. Desse modo, fecha-se um círculo vicioso, nocivo à editoração do país, promovendo-se-lhe a sangria, a drenagem do que melhor existe em sua produção, em benefício dos agentes já blindados e titulados como dignos dessa preferência de reconhecimento. Mais ainda difícil se torna vencer esse contingenciamento quando a publicação se faz, como a dos Arquivos Brasileiros de Oftalmologia, numa língua periférica à da comunidade científica mundial. Essa, por exemplo, sempre foi uma tentação, a de (justificadamente pelo prisma acadêmico), passar a produzir um Brazilian Archives of Ophthalmology, todo em inglês, a língua universal da ciência, o que poderia impulsionar a revista em sentido da indexação, facilitando a divulgação e impacto de seus artigos. Contra a opção de oferecer, sim, aos autores que desejassem, tal condição de uso do inglês (e do espanhol) mas sem torná-la compulsória, sem subjugar o brasileiro a abdicar de sua língua mãe, para publicar numa revista de "seu" país. Fizemos, afinal, a escolha pelo caminho mais difícil, a aposta de que conviria o reforço de quadros nacionais de autores e revisores pela reverberação de seus produtos, uma justificativa pedagógica (que, aliás, também e sobretudo é o sentido teleológico do saber acadêmico).

Uma das condições importantes nesse caminho de sobrevivência editorial e do reconhecimento internacional foi haver conseguido -- outro de nossos orgulhos - nossa revista selecionada pela SciELO (Scientific Electronic Library Online), iniciativa brasileira que agora se estende pela América Latina e pelo mundo e que, certamente, fundamenta a conquista de agora. É por isso que, nesta hora de alegria, ganha também especial relevo a presença do fundador dos Arquivos Brasileiros de Oftalmologia, com sua intenção - inicial mas perene de que os objetivos da revista se expressassem com um sentido bem amplo, mas nos quais a preservação de valores pátrios parece ficar bem evidente. De fato, na primeira página do primeiro número da revista, dando sua apresentação e estatuto, Waldemar Belfort Mattos escrevia "Os Arquivos Brasileiros de Oftalmologia aparecem com as seguintes finalidades: a) dar publicidade aos trabalhos originaes dos oculistas patrícios; b) transmitir a todos os médicos brasileiros, interessados pela especialidade, o que existir de mais moderno no campo da oftalmologia mundial; c) fomentar o estudo e o aperfeiçoamento de oftalmologia". Depois justifica a escolha do símbolo distintivo da revista, homenageando "...dissemi- 
nadores da primitiva civilisação brasileira", para concluir: "Assim tambem, com um destes mesmos simbolos em seu frontespicio, os Arquivos Brasileiros de Oftalmologia se espalharão por todo o Brasil, promovendo e fomentando, entre todos, o intercambio da oftalmologia patria". Passaram os tempos, mudaram as formas, mas permanece a essência. Receber, assim, o galardão de "very good", a classificação com que os Arquivos Brasileiros de Oftalmologia foram agraciados por sua entrada na MEDLINE, tornando-se, aí, a única publicação latino-americana do gênero e uma das poucas brasileiras, das cerca de quinhentas, em toda a área da saúde (na MEDLINE apenas 17, das quais algumas publicadas inteiramente em inglês) é, portanto, duplamente reconfortante: ganha-se por causa do conteúdo e apresentação da revista; mas ganha-se, também, apesar da língua em que ela é publicada. Ganha-se pelo mérito, mas ganha-se na auto-estima de uma nação, pela condição como isso se fez.

Não há, então, razões para susto. Pois já tivemos que responder a questões como a de que "e agora, só deveremos publicar em inglês?" Nada muda. Não há imposições. Um autor brasileiro não precisará, doravante, enviar seu artigo para robustecer, ainda mais, um órgão estrangeiro e ter, então, maior reconhecimento de seus feitos (por sua Universidade, por agências financiadoras de estudos, pela comunidade de seus pares): os Arquivos Brasileiros de Oftalmologia passam a oferecer os mesmos índices de qualificações. Seus artigos ganharão reputação e visibilidade aumentada.

É provável - pela vitrine que agora se abre, escancarando a produção oftalmológica brasileira à leitura internacional - que mais autores prefiram expor seus trabalhos em modo a que sejam apreciados na íntegra, não apenas por seus resumos. Conjeturase, então, que possa haver — se houver - um aumento dos artigos de nossa revista em inglês. Mas livre e espontaneamente. Mais que uma questão de conceito, uma profissão de fé, um jeito de ver o mundo e as pessoas que nele estão.
Em suma, não foi uma simples conquista dos Arquivos Brasileiros de Oftalmologia, mas de toda a Oftalmologia brasileira. Cujo reconhecimento internacional, como o que agora acontece, lhe é, há muito, devido. A habilidade de numerosos colegas, notabilizados mundialmente por seus altos padrões de desempenho clínico e cirúrgico; a inspirada e cuidadosa busca da expansão das fronteiras do saber, em nossos laboratórios; a crescente e bem qualificada massa crítica de autores e revisores científicos é quem se fez merecedora desse prêmio e desse crédito, do qual os Arquivos Brasileiros de Oftalmologia, se faz veículo.

Sentir-se em estado de graça só pode ser isso: alcançar o sonhado objetivo ao fim de uma dura jornada; provar que a convicção em valores, remando contra as correntezas, não é uma esperança utópica; saber o dever cumprido na conclusão da missão; antever quantos (muitos talvez ainda insuspeitados) benefícios possam ser gerados e espalhados, atingindo gerações; transcender ao "aqui e agora". E é aí que mora, com a glória, a responsabilidade: de, doravante, e muito mais explicitamente, no concerto internacional, mostrar a que veio a Oftalmologia brasileira.

A ela, Oftalmologia brasileira, as congratulações pela expressiva vitória e nossos agradecimentos pela imensa honra de termos podido trazê-la. E ao Conselho Brasileiro de Oftalmologia, as especiais reverências às suas diretorias que sempre confiaram na independência de ação de sua revista e que, sobretudo, garantiram por seus apoios logístico e financeiro todas as circunstâncias para que se alcançasse o brilho do conteúdo científico, a qualidade da formatação, a regularidade de nossas publicações e de suas distribuições. Nunca é demais insistir na ação indispensável do Conselho Brasileiro de Oftalmologia para a continuidade e progressiva melhora do nosso Arquivos Brasileiros de Oftalmologia. Nunca é demais agradecer às várias diretorias do Conselho Brasileiro de Oftalmologia e o fazemos aqui com o mais profundo e sincero sentimento de gratidão.

\section{SIMPÓSIO INTERNACIONAL DE CIRURGIA PLÁSTICA OCULAR, PÁLPEBRA, ÓRBITA, VIAS LACRIMAIS E NEUROFTALMOLOGIA}

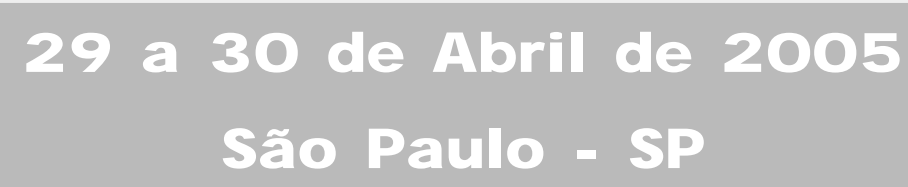

\section{IN FO RMAÇõ ES: Tel.: (11) 5085-2026 e 5085-2087}

